\title{
SERIA HUET O MODELO DO ABADE FILOSÓFICO DA NOTA B DO VERBETE PIRRO?
}

\author{
José R. Maia Neto* \\ jrmaia@ufmg.br
}

RESUMO O texto de Bayle mais frequentemente citado como contendo o seu ceticismo mais radical é a nota $B$ do artigo Pirro do Dicionário Histórico e Crítico. A filosofia cética presente nesta nota é dramaticamente apresentada por um abade católico em diálogo com outro abade. $O$ artigo reúne considerações históricas, biográficas, bibliográficas e filosóficas que dão plausibilidade à hipótese que Pierre-Daniel Huet (1630-1721) foi o modelo histórico do personagem bayleano. Estas considerações contribuem para esclarecer a questão, bastante controversa, da natureza e escopo do ceticismo da nota $B$ do artigo Pyrrho.

Palavras-chave Bayle, Huet, ceticismo, pirronismo, fideísmo.

ABSTRACT Bayle's text most often cited as indicative of his most radical skepticism is remark $B$ of the article Pyrrho of the Dictionary Historical and Critical. The skeptical philosophy exhibted in this Remark is dramatically presented by a Catholic abbot in a dilogue with another abbot. The article brings together historical, biographical, bibliographical and philosophical considerations that make plausible the hypothesis that PierreDaniel Huet (1630-1721) was the historical model for Bayle's character. These considerations contribute to clarify the much controversial issue of the nature and scope of the skepticism exhibited in Remark $B$ of the Pyrrho article.

Keywords Bayle, Huet, skepticism, pyrrhonism, fideism.

* Departamento de Filosofia/UFMG, CNPq. Recebido em 17/09/2009 e aceito em 15/10/2009.

KRITERION, Belo Horizonte, no 120, Dez./2009, p. 349-362. 
Gostaria inicialmente de ressaltar a forma interrogativa do título deste artigo. Não tenho elementos para afirmar que Huet tenha sido o modelo do abade filosófico da nota B do artigo Pirro. Bayle pode ter se inspirado em outra pessoa, em várias ou em nenhuma. $\mathrm{O}$ que farei aqui será apontar alguns indícios que dão plausibilidade à hipótese de Huet ter sido o modelo do abade filosófico, se é que houve um. Outro ponto incial diz respeito à questão da historicidade do diálogo entre os dois abades supostamente testemunhada pelo "habile homme" que a teria relatado a Bayle. As considerações que faço aqui independem da historicidade do evento. Mesmo tendo sido todo o diálogo imaginado por Bayle, ainda assim tanto a caracterização dos interlocutores como as posições por eles defendidas podem ter sido - e é natural que tenham sido - inspiradas ou modeladas em filósofos reais contemporâneos de Bayle. Minha suspeita — que infelizmente não foi possível comprovar-é que Bayle reconstrói na nota $\mathrm{B}$, a partir de sua própria visão da questão das relações entre ceticismo e cristianismo, um diálogo do qual ouviu dizer ter de fato ocorrido ou imaginou a possibilidade de ter ocorrido a partir de informações de que dispunha. ${ }^{1}$ A hipótese que proporei é que uma provável fonte de Bayle é algum manuscrito do Traité philosophique de la foiblesse de l'esprit humain de Pierre Daniel Huet (1630-1711) que teve em mãos ou do qual ouvir falar. Faço, a seguir, algumas considerações sobre o verbete Pirro e a nota B a fim de propor o que penso ser o objetivo do abade filosófico com seus paradoxos. Em seguida aponto fatos biográficos e bibliográficos que dão plausibilidade à hipótese de Huet ter servido como modelo.

É necessário distinguir dois textos: o verbete Pirro em seu conjunto e as notas B e C.

1 Acho improvável a afirmação de Popkin de que o "savant théologien", presente no debate dos dois abades, é o próprio Bayle. Em primeiro lugar é necessário observar que o "habile homme" testemunha do diálogo e suposta fonte de Bayle pode ou não ser—nada é dito a este respeito—o "savant théologien" cuja intervenção no debate entre os dois abades conclui a Nota B. Popkin diz que a revelação que o "savant théologien" é o próprio Bayle é feita no Entretiens de Maxime et de Themiste (ver Bayle, Pierre. Dictionary: Selections. Tradução e notas de Richard H. Popkin. Indianapolis: Hackett, 1991. p. 204n). Suponho que Popkin tinha em mente a seguinte passagem dos Entretiens: «Mr. Le Clerc veut que les consequences que l'Abbé Pyrrhonien tire dans le Dictionnaire soient les sentimens de Mr. Bayle, \& nous voions tout le contraire, car la consequence que Mr. Bayle tire apres avoir fait parler le Pyrrhonien, est celle-ci 'qu'il faut avant toutes choses faire sentir aux Pyrrhoniens l'infirmité de la raison afin que ce sentiment les porte à recourir à un meilleur guide qui est la foi'» (Bayle, Pierre. Entretiens de Máxime et de Themiste. Rotterdam: Reinier Leers, 1707. p. 112-113). Este texto distingue a posição do abade filosófico da nota B da de Bayle, aqui identificada com a posição do "savant théologien". Há identificação das posições, não dos indivíduos. 
O verbete é, à primeira vista, típico do Dicionário. Bayle apresenta Pirro, se apoiando, sobretudo, na "Vida de Pirro" de Diógenes Laércio." Cita a maioria das anedotas reportadas por Diógenes Laércio sobre Pirro, contestando aquelas, oriundas de Antígono de Caristo, que põem em questão a viabilidade prática do pirronismo. Somente as notas B e C são digressões filosóficas. ${ }^{3}$ A nota B é introduzida na frase do verbete em que Bayle afirma que "c'est avec raison qu'on ... deteste [o pirronismo] dans les écoles de théologie". Podemos inferir desta afirmação que Bayle acha o pirronismo incompatível com o cristianismo? Penso que sim no caso de um pirronismo pleno, mas não no caso de uma apropriação parcial (mas não necessariamente menos radical) do pirronismo. A afirmação permite inferir uma inconsistência mais radical do pirronismo com a teologia natural, isto é, com o discurso racional sobre Deus, seus atributos e suas relações com o mundo. Bayle adota neste ponto uma posição semelhante à dos céticos antigos, ${ }^{4}$ mas vai mais além na nota $\mathrm{B}$, acrescentando razões porque o ceticismo seria inócuo contra a religião. Bayle ressalta a força de fatores não epistêmicos na formação das crenças do homem

2 Bayle segue Diógenes Laércio ao não estabelecer diferenças filosóficas entre os ceticismos de Pirro e de Sexto.

3 A nota A cita Aulo Gélio para afirmar que há uma pequena diferença entre os pirrônicos e acadêmicos, mas que Arcesilaus é muito próximo dos pirrônicos. A nota $D$ ataca as anedotas de Antígono de Caristo contra a vida de Pirro (que precisava de amigos para desviá-lo dos precipícios, etc.), citando a defesa da viabilidade da vida de Pirro feita por La Mothe Le Vayer na Vertu des Payans. A nota E trata da indiferença de Pirro. Cita o elogio de Anaxarco por Pirro não ter se abalado quando ele, Anaxarco, caiu num buraco e levanta a questão de se Pirro manteria a indiferença mesmo em face da morte. Bayle argumenta que sim, citando a anedota que Pirro teria comparado a tranqüilidade do sábio pirrônico à de um porquinho em um navio na tempestade. A nota F destaca a perspectiva de Pirro sobre a vaidade das coisas, citando sua admiração pelo verso de Homero que compara os homens às folhas levadas para cá e para lá pelo vento e aos mosquitos e pássaros. Bayle diz que este ponto é pirrônico, pois mostra a instabilidade do espírito dos homens. Aproveita a nota para atacar o seu principal desafeto na comunidade protestante francesa no exílio, Pierre Jurieu que, segundo Bayle, argumenta deste modo, adotando princípios diversos conforme a necessidade da ocasião. A nota $\mathrm{G}$ é sobre o compartilhamento das tarefas domésticas com a irmã e sua atitude face às mulheres (não que as desprezasse, mas a atitude que tomava variava em função do sexo). A nota $\mathrm{H}$ é bem curta: mostra a causa do erro de se atribuir a Pirro a concessão da cidadania ateniense. A nota I faz cinco correções menores em Moreri. Por fim, a nota K (não há J) cita passagens de Epíteto sobre Pirro: por um lado, o estóico admirava a indiferença do cético em relação à morte, mas, por outro, atacou muito os pirrônicos.

4 Esta posição é compartilhada por céticos pirrônicos e acadêmicos. "For perchance the Sceptic, as compared with philosophers of other views, will be found in a safer position, since in conformity with his ancestral customs and the laws, he declares that the Gods exist, and performs everything which contributes to their worship and veneration, but, so far as regards philosophic investigation, declines to commit himself rashly" (Sexto Empírico, Adversus Mathematicos IX.49). Ver também os Esboços do Pirronismo III.2. (As duas obras foram traduzidas por E. Bury e publicadas na Loeb Classical Library. Cambridge, MS: Harvard U. Press, 1933). No caso do ceticismo acadêmico, Cota, porta voz da Academia no De Natura Deorum de Cícero, faz em III.5 a mesma distinção entre religião tradicional (que ele aceita plenamente) e discussões filosóficas sobre Deus (que ele examina e problematiza). Ver a edição bilíngüe latim/inglês do De Natura Deorum, traduzida por H. Rackham e publicada na Loeb Classical Library. Cambridge, MS: Harvard U. Press, 1933). 
comum. ${ }^{5}$ Assim é que uma crítica filosófica das crenças religiosas dificilmente teria impacto nas crenças da grande maioria dos homens e mulheres. No corpo do verbete ainda consta que o pirronismo "tâche de puiser de nouvelles forces" justamente na teologia (a especificação destas forças na nota B deixa claro que se trata da teologia positiva ou revelada), "qui ne sont que des chimères: mais il peut avoir ses usages pour obliger l'hommme, par le sentiment de ses ténèbres, à implorer le secours d'en haut, et à se soumettre à l'autorité de la foi" (com a chamada para a nota C). Assim, se um pirronismo puro é incompatível com o cristianismo, ele é dificilmente adotado pelo homem comum e pode ser instrumentalizado pelo filósofo a favor da religião.

A Nota B é um diálogo para o qual Bayle, nos Entretiens de Máxime et de Themiste, reivindica uma autonomia dos interlocutores (os dois abades) e destes em relação ao autor (Bayle). Esta é uma chave de leitura que me parece interessante e a qual voltarei. Entretanto, é necessário ter em mente que a caracterização do abade que levanta os paradoxos na nota B no Dicionário difere da caracterização deste mesmo abade nos Entretiens. Neste último livro de Bayle, publicado postumamente em 1707, isto é, dez anos após a publicação do verbete "Pirro", Bayle responde às objeções levantadas pelos teólogos "racionaux" Jacquelot e Le Clerc contra - entre outros pontos - o "pirronismo" do Dicionário. É Le Clerc quem primeiro qualifica o "abade filosófico" da nota B como o "abade pirrônico", cuja posição identifica com a do autor do Dicionário. A passagem em que Bayle distingue de forma acentuada os dois abades é uma resposta à objeção específica de Le Clerc que o fato de Bayle colocar no mesmo plano os mistérios da queda de Adão, da transmissão do pecado original, da encarnação, da trindade e da eucaristia, significa que ele rejeita os quatro primeiros, pois é a mesma razão que determina a rejeição do último (a eucaristia).

[Jacquelot e LeClerc] supposent qu'il [l'Abbé Pyrrhonien] veut montrer que les mysteres du Christianisme sont faux, \& il est clair que la dispute ne tend qu'à ceci, c'est que la verité de ces mysteres prouve qu'il y a des axiomes qui sont tout ensemble faux et évidens, d'où il conclut que les Dogmatiques qui soutienent que l'évidence est le caractere de la verité se trompent. Il faut se souvenir qu'il dispute avec un Abbé bon Catholique Romain, \& qu'il argument contre lui ad hominem en consequence des mysteres. S'il s'étoit donc prevalu des avantages qu'il esperoit de tirer de ce que son Antagoniste croioit la chûte d'Adam, le peché d'origine, la Trinité, l'Incarnation, $\&$ qu'il eut gardé un profond silence à l'égard de la Transubstantiation qui lui pouvoit

5 Bayle cita os seguintes fatores: "la grace de Dieu dans les fidèles, la force de l'éducation dans les autres hommes, ... l'ignorance et le penchant naturel à décider». 
fournir les meilleurs armes, il n'y a personne qui ne se fut recrié qu'on le faisoit agir un sot \& en bête. ${ }^{6}$

Neste contexto polêmico com Le Clerc, Bayle está na defensiva, tratando, sobretudo, de diferenciar a sua posição pessoal das distintas posições dos dois abades: do católico (que aceita todos os mistérios, inclusive a eucaristia) e do pirrônico. Este último aparece como argumentando ad hominem, portanto não como um cristão, mas como um opositor especificamente pirrônico. Assim é que a verdade dos mistérios não está em questão para o abade pirrônico, somente a evidência como critério de verdade. A verdade dos mistérios é pressuposta pelo abade católico e o abade pirrônico se engaja com o católico como um pirrônico, isto é, desprovido de qualquer crença, seja a favor, seja contrária à verdade dos mistérios. A situação é diferente na nota $\mathrm{B}$ na qual os dois interlocutores são caracterizados como abades católicos. $\mathrm{O}$ abade filósofo jamais se coloca como pirrônico, nem é taxado como tal, seja por Bayle, seja pelos demais personagens da nota. ${ }^{7}$ Esta distinção é relevante porque se caracterizarmos o abade filosófico da nota $\mathrm{B}$ como um pirrônico estrito, tal como ele aparece nos Entretiens, fica diminuída a probabilidade de Huet ter sido o modelo. Bayle sabia bem que Huet não era um puro pirrônico mas bom católico.

O uso da forma dialogal para a discussão do ceticismo é bastante difundido no período. O modelo antigo são os textos de Cícero sobre os céticos acadêmicos. O modelo moderno publicado mais relevante é a obra de La Mothe Le Vayer, Dialogues faits à l'imitation des anciens, cuja impressão "d'impieté" Bayle comunicou a seu irmão Jacob em 1675. ${ }^{8}$ No mais libertino destes diálogos, o "Diálogo sobre a Divindade", o interlocutor não cético (Orontes) diz que só não aceita o pirronismo defendido por Orasius por causa de sua incompatibilidade com a religião, escrúpulo que Orasius se dispõe a

6 Bayle, Pierre. Entretiens de Máxime et de Themiste. p. 103-104.

7 O abade filosófico se refere à "notre théologie" [ênfases minha] e chega mesmo a criticar o pirronismo. "On [presumo que Bayle se refere ao abade filósofo] lui [ao abade rotineiro] répliqua modestament qu'on savait bien que ce n'étaient que des sophismes, et de très-petits difficultés». O abade filosófico parece assim como um abade católico fazendo o papel de filósofo pirrônico contra a afirmação específica do abade rotineiro que o cristianismo aboliu o ceticismo.

8 "Je lues a Rouen les Dialogues d'Orasius Tubero imprimés. II y a bien de l'erudition, mais il y a encore plus d'impieté. Ce sont des coups de jeunesse, je l' avoue, je ne sai pourtant pas si l' author s'en est repenti, car toute sa vie il a ecrit a la deffense du pirrhonisme d'une maniere qui ne sentoit pas son ame forte devote. Je tiens Mr de La Mothe Le Vayer et Mr Naudé pour les 2 savans de ce siecle qui avoient le plus de lecture et l'esprit le plus epuré des sentimens populaires, mais parce qu'ils font trop les esprits forts, ils nous debitent bien souvent des doctrines qui ont de perilleuses consequences». Carta de Bayle a Jacob de Paris, 21 juillet 1675. (Correspondance de Pierre Bayle. Publieé et annoteé par E. Labrousse et al. Oxford: Voltaire Foundation, 2001. vol I, carta 105, p. 250-252). 
desfazer. $\mathrm{O}$ contexto é assim semelhante ao do diálogo da nota $\mathrm{B}$, sendo que La Mothe é citado (embora não esta obra) na nota $\mathrm{C}$, observando, justamente, que "le systeme sceptique fondé sur une naive reconnaissance de l'ignorance humaine, [est] le moins contraire de tous à notre créance".

Dois outros diálogos que tratam do uso apologético do ceticismo já existiam em manuscrito quando Bayle escreveu o verbete Pirro do Dicionário. Embora o fato de não terem sido ainda publicados torne menos provável que Bayle os tenha conhecido, há semelhanças notáveis entre ambos e a nota B. Estes diálogos são o Entretien de Pascal avec Sacy, extraído das Mémoires de Nicolas de Fontaine (1625-1709), secretário do jansenista Lemaistre de Sacy (1613-1684) e o Traité philosophique de la foiblesse de l'esprit humain de Huet. ${ }^{10}$

É praticamente impossível que Bayle tenha tomado conhecimento do Entretien de Pascal avec Sacy, sobretudo antes da redação do verbete Pirro. Tanto o período da redação do manuscrito (não antes de 1696) como a circunstância de sua redação (retirada, aparentemente sem muita circulação), conspiram contra a hipótese de Bayle ter conhecido o texto. Entretanto, há similaridades dignas de nota entre os dois diálogos. O tema é o mesmo: a relação do ceticismo com o cristianismo, em particular a possibilidade de um uso apologético do ceticismo antigo. Os personagens são também semelhantes. No Entretien de Pascal avec Sacy há também dois interlocutores: um filosófico que argumenta que o cristianismo em certo sentido limitado fortalece o pirronismo, ${ }^{11}$ e Sacy, abade piedoso de Port-Royal, que despreza a filosofia e inicialmente se escandaliza com o uso apologético do ceticismo. Na nota B, após ouvir parte da exposição do abade filosófico, o abade rotineiro diz “qu'il pardonnait aux philosophes du paganisme d'avoir flotté dans l'incertitude des opinions; mais qu'il ne pouvait comprendre que, sous la lumière de l'évangile, il se trouvât encore de misérables pyrrhoniens». Sacy reage de forma idêntica ao relato de Pascal do ceticismo fideísta de Montaigne: "On pardonnerait à ces Philosophes d'autrefois, qu'on nommait académiciens, de mettre tout dans le doute. Mais qu'avait besoin Montaigne de s'égayer l'esprit en renouvelant une

9 Bayle cita La vertu des payans, tome V das Oeuvres de La Mothe Le Vayer (Dresden: M. Graell, 1756-59). Outros diálogos céticos ou sobre o ceticismo que Bayle leu ou poderia ter lido são o Quod nihil scitur (1581) de Francisco Sanches, La Verité des sciences contre les sceptiques ou pyrrhoniens (1625) de Mersenne, The Sceptical Chemist (1661) de Robert Boyle.

10 O Traité philosophique foi publicado em 1723 em Amsterdã e o Entretien avec Sacy foi publicado em 1728 em Utrecht. Fontaine compôs a suas memórias quando se retirou nas cercanias de Paris, entre 1696 e 1700, ano do seu falecimento (cf. Mesnard, Jean, introdução à sua edição do Entretien in Pascal, Blaise. Oeuvres complètes. Paris: Desclée de Brower, 1991. Vol. II, p. 83n2).

11 Para Pascal o pirronismo é parcialmente consistente com a doutrina cristã, embora seja totalmente incompatível do ponto de vista moral. 
doctrine qui passe maintenant aux chrétiens pour une folie?». ${ }^{12}$ Contrapondose à afirmação de Pascal que segundo Montaigne mergulhamos na completa incerteza se colocamos a fé de lado, Sacy diz que Montaigne "met dans tout ce qu'il dit la foi à part; ainsi nous, qui avons la foi, devons de même mettre à part tout ce qu'il dit». ${ }^{13}$ Quando levamos a sério o caráter dialogal da nota $\mathrm{B}$ e a comparamos com o Entretien avec Sacy, fica clara a retorção que o abade filosófico faz da posição do abade rotineiro. É justamente ao não se colocar a fé cristã de lado, mas, ao contrário, pressupô-la como verdadeira, que o ceticismo se fortifica. Proponho assim uma leitura minimalista da nota $\mathrm{B}$, que não implica nem uma intenção apologética nem uma anti-religiosa. $\mathrm{O}$ abade filosófico na nota $B$ não é nem propriamente pirrônico nem propriamente cristão, mas simplesmente faz a retorção do primeiro abade. Ele reverte a tese deste último - a mesma de Sacy—que após a revelação já não cabe qualquer ceticismo. Esta leitura é consistente, primeiro, com o conjunto do verbete-incluindo as demais notas - cuja tendência é defender a viabilidade do pirronismo. A leitura é também consistente com a tese de Frédéric Brahami que o ceticismo moderno é fortemente marcado em sua origem pelo cristianismo. ${ }^{14}$ A nota B vai além do ceticismo de Montaigne-que a verdade está em um Deus totalmente transcendente - argumentando que a revelação deste Deus coloca em questão princípios da razão humana. ${ }^{15}$ Precisamos, entretanto, diferenciar a posição do abade filosófico da de Pascal, para quem os mistérios cristãos do pecado de Adão e da transmissão do pecado original vão de encontro a uma razão a priori mas ao encontro de uma razão a posteriori, pois 'l'homme est plus inconcevable sans ce mystère, que ce mystère n'est inconcevable à l'homme". ${ }^{16}$ A posição de Bayle no verbete Maniqueístas é inversa à de Pascal: a razão a posteriori é contrária e a razão a priori favorável ao cristianismo. ${ }^{17}$

A probabilidade de Bayle ter lido ou pelos menos ouvido falar do manuscrito do Traité philosophique de Huet é bem maior. Bayle conheceu

12 O ceticismo que Sacy conhece é o da nova academia. Curiosamente, logo após a fala do abade rotineiro acima citada, o abade filosófico imagina o retorno de Arcesilaus e não o de Pirro.

13 Pascal, Blaise. Entretien avec Sacy in Oeuvres completes, vol. III, p. 145.

14 Sobre a questão das relações entre ceticismo e cristianismo, a posição de Bayle parece ser a mesma da de La Mothe Le Vayer e de tantos outros: que o pirronismo em si é contrário à religião, mas que pode ser instrumentalizado a seu favor (embora haja diferenças notáveis sobre esta instrumentalização).

15 A tese de Bayle é mais ampla que a de Montaigne, que centra-se na transcendência e onipotência do Deus cristão. Bayle explora as implicações céticas destes atributos e dos mistérios cristãos.

16 Pascal, Blaise. Pensées. Texte établi par Louis Lafuma. Paris: Éditions du Seuil, 1963, fragmento La 131.

17 Pascal é também citado na nota $\mathrm{C}$ como exemplo da apologética seguida por Bayle. Entretanto, os usos apologéticos do ceticismo por Pascal e Bayle são bem diferentes. Ver Maia Neto, José. "O Ceticismo de Bayle", Kriterion 35 (1996): 77-88. 
Huet em Paris em 1675, poucos meses após retornar de Genebra. ${ }^{18}$ Como mostram os biógrafos de Bayle Elisabeth Labrousse e Hubert Bost, Bayle foi acolhido na França por huguenotes da Normandia, mesma região de Huet, cujo pai era um calvinista convertido ao catolicismo. ${ }^{19}$ Obteve o posto de preceptor dos filhos de uma viúva de um rico comerciante de Rouan, prima de Moisant de Brieux, fundador da Academia de Caen. Huet, que também era de Caen, participou ativamente desta Academia. Fora do meio huguenote, Bayle conheceu o influente erudito Gilles Ménage, grande amigo de Huet. Bayle conheceu pessoalmente Huet em Paris na casa de Henri Justel, erudito e promotor de reuniões científicas. Quando se conhecerem em 1675, Bayle estava tentanto se inserir na República das Letras ao passo que Huet já era um dos seus mais ilustres cidadãos. Conhecido dos salões e academias, já era autor de De interpratione (1661), Origenis Commentaria (1668), De l'Origine des Romans (1670) e de um Discours prononcé à l'Academie Françoise (1674). Quando se conheceram, tinham a mesma ocupação em Paris: ambos eram preceptores, Bayle dos filhos de Beringher, secretário do rei; Huet subperceptor do filho do rei. Neste mesmo ano em que se conheceram, Bayle trocou o emprego de preceptor por uma cátedra na Academia protestante de Sedan, mas continuava a ir esporadiamente a Paris até o seu exílio definitivo na Holanda em 1681. Um ano antes, Huet terminou o seu sub-preceptorado e, tendo se ordenado padre em 1676, recebeu a abadia de Aulnai (próxima de Caen), onde redigiu a primeira versão do Traité philosophique.

Já estabelecido em Roterdam, na resenha de um livro de Louis Thomassim, ${ }^{20}$ publicada nas Nouvelles de la République des Lettres (Maio 1686), Bayle cita a seguinte passagem de Simon Foucher:

[Foucher] finit [sua resposta a Desgabetes e a Malebranche] en souhaitant que M. Huet 's'acquitte bien-tôt de la promesse qu'il a fait de faire voir que les Sectes de Philosophie qui apprennent à douter s'accordent mieux que les autres avec le Christianisme'.

Esta promessa foi feita por Huet no prefácio da Demonstratio Evangelica, obra publicada no mesmo ano do livro de Foucher citado por Bayle. ${ }^{21} \mathrm{~A}$

18 Ver carta a Louise Marcombes, 1 juillet 1675 in Bayle, Pierre. Oeuvres diverses, 1727,-- Corresp. T II, p. 222 e para Minutoli, 1 juillet 1675, T. IV, p. 594-97.

19 Labrousse, Elisabeth. Pierre Bayle, T. I. Du Pays de Foix à la cité d'Érasme. La Haye: Martinus Nijhoff, 1963 (cap. 5, esp. p. 122-130); Bost, Hubert. Pierre Bayle. Paris: Fayard, 2006. (cap. 4, esp. p. 94-113)

20 La Méthode d'étudier et d'enseigner chrétienement (Paris, 1685).

21 Foucher, Simon. Réponse pour la Critique à la preface de la Recherche de la Verité. Oú l'on examine le sentiment de M. Descartes touchant les idées. Avec plusieurs remarques utiles pour les Sciences. Paris: Robert J. B. de la Caille, 1679; Huet, Pierre-Daniel. Demonstratio Evangelica. Paris: S. Michallet, 1679. 
promessa acabara de ser cumprida em Aulnai exatamente quando Bayle destacava-a nas Nouvelles. Com efeito, em 1686 Huet já possui o manuscrito quase completo da versão original das Quaestiones Alnetanae, cujo primeiro livro era justamente o texto que recebeu posteriormente o título de Traité Philosophique. Entretanto, reações críticas de amigos próximos levaramno a não publicar esta primeira parte cética junto com as demais, que foram publicadas desmembradas, uma parte na Censura Philosophiae Cartesianae (1689) e outra nas Quaestiones Alnetanae (1690). Após a publicação deste último livro, Huet ainda tentou publicar o Tratado, sob o título de uma “Quarta questão de Aulnai” em 1691. Huet escreve então um prefácio para esta Quarta Questão, articulando-a ao contexto dramático da obra de 1690. Este prefácio só foi publicado postumamente em $1726,{ }^{22}$ pois novas reações contrárias à publicação, sobretudo pelo censor da Sorbonne Edme Pirot, abortaram o projeto. ${ }^{23}$

O prefácio escrito por Huet para a Quarta Questão de Aulnai (posteriormente, Traité philosophique), pode iluminar a questão do modelo de Bayle para o diálogo dos abades na nota B. Em primeiro lugar, Huet dá um contexto ficcional ao texto, que seria um diálogo ocorrido nos jardins da abadia de Aulnai entre Huet, o abade filosófico de Aulnai, e dois outros religiosos seus amigos: o jesuíta Pierre Gautruche (professor de filosofia do colégio jesuíta de Caen, forte opositor do ceticismo), e o oratoriano Jean-Baptiste Du Hamel, também caenaense, membro da Academia de Ciências de Paris, defensor de uma via média entre ceticismo e dogmatismo e conciliador da velha com a nova filosofia. ${ }^{24}$ De acordo com o prefácio, a filosofia cética do diálogo seria então relatada por Du Hammel, com base no que ouviu de Louis de Cormis, político de Aix-en-Provence exilado em Caen nos anos 60, quando se tornou amigo de Huet a quem introduziu o pensamento cético de Sexto Empírico. Um segundo ponto digno de nota no prefácio é o fato de Huet nele introduzir o diálogo como a realização da promessa que havia feito na Demonstratio Evangelica, e anunciada por Bayle nas Nouvelles de la Republique de Lettres, de mostrar a maior compatibilidade do cristianismo com o ceticismo do que

22 Continuation des Memoires de Litterature et d'Histoire de M. de Salengre, Tome II, Partie I, Paris: Simart, 1726. p. $485-493$

23 Relato as peripécias da redação, revisões e publicação do Traité philosophique no capítulo "Charron and Huet: two still unexplored legacies of Popkin's scholarship on early modern skepticism" in Jeremy Popkin, (ed.). The Legacies of Richard Popkin. Dordrecht: Springer, 2009. p. 137-152.

24 Du Hamel é autor de um De consensu veteris et novae philosophiae (1663) e de uma Philosophia vetus et nova ad usum scholae accomodata (1678). Sobre Du Hamel e suas relações com Huet, ver Rapetti, Elena. Percorsi anticartesiani nelle lettere a Pierre-Daniel Huet. Firenze: Leo Olschki, 2003. p. 143-169. Sobre Gautruche e suas relações com Huet, ver Shelford, April. Transforming the Republic of Letters. PierreDaniel Huet and European Intellectual Life, 1650-1720. Rochester: Rocherster U. P., 2007. p. 116-117. 
com as outras escolas filosóficas. Este exemplar da Nouvelles de la Republique de Lettres consta, com vários outros, na relação da biblioteca pessoal de Huet, segundo o inventário preservado na Biblioteca Municipal de Caen. ${ }^{25}$

A referência a Huet mais importante na correspondência de Bayle é feita em uma carta de 1694 (dois anos depois da redação do prefácio de Huet) a Mme de Tilly, huguenote erudita de Caen exilada na Holanda, amiga comum dos dois filósofos. ${ }^{26}$

J'ai une ... grace à vous demander Madame, c'est que la premiere fois que vous ecrirez à Monseieur l'Eveque d'Avranches vous aiez la bonté de l'assurer des profonds respects que j'ai pour lui, et de l'admiration continuelle où je suis de ses eminentes qualitez, de son savoir immense, de sa belle Latinité, de ses vertus, et de tout ce en un mot qui fera un jour la matiere de plus bel Eloge qu'on ait jamais fait d'un Prelat de l'Eglise Gallicane. Je me fais un plaisir incroiable de marquer ces sentimens dans mon Dictionnaire lors que l'occasion de parler de lui et de le citer me sera offerte. Mr. Basnage n'a pas manqué de me faire savoir les honnetetez de ce grand homme pour moi; comme vous l'en aviez chargé.

Quando redige esta carta, Bayle está justamente trabalhando no Dicionário Histórico Crítico, cujos primeiros dois volumes (até a letra P) foram colocados em venda em 1696. ${ }^{27}$ Bayle diz na carta que terá um "plaisir incroiable" de fazer o "éloge" de Huet no Dicionário. Popkin observa que tal éloge não foi feito, ${ }^{28}$ o que é correto, exceto se não foi reduzido à afirmação que "M. Huet, évêque d' Avranches, ... est un grand juge en toutes matiéres", ${ }^{29}$ ou se a construção do personagem do abade filosófico da Nota B for este "plus bel Eloge qu'on ait jamais fait d'un Prelat de l'Eglise Gallicane». ${ }^{30}$ Popkin duvida que Bayle

25 Biblioteca Municipal de Caen, ms in 4․ 207.

26 A carta foi descoberta por Popkin e publicada no artigo "Un Unpublished Letter of Pierre Bayle", Nouvelles de la Republique des Lettres (1981-2). p. 193-197. Sobre Mme. De Tilly e Huet, ver Shelford, April. op. cit.. chap. 3, p. 77-113.

27 Apud Labrousse. op. cit. p. 244-245.

28 Popkin. op. cit. p. 194.

29 Dicionário, verbete Longus. A menção ocorre no contexto do exame das Pastorales de Longus. Bayle cita De l'Origine des Romans de Huet (Paris: 1670, p. 65-66) onde Huet afirma ter desistido de traduzir esta obra por causa das obscenidades nela contidas.

30 Nicaise manteve Huet informado das atividades de Bayle na República das Letras. Assinala com destaque a Huet a aparição do Projeto do Dicionário e diz que Bayle mandaria um exemplar "para nós" e outro para outro amigo comum a Bayle e Huet, Gilles Ménage. (Carta de Nicaise a Huet, 29 juillet 1692, publicada por Pélissier, Léon-Gabriel. Lettres inédites de Claude Nicaise à Huet et à G. Bonjour. Dijon, 1889). Ménage compartilhava com Huet em correspondência uma grande simpatia pelo ceticismo antigo, revelada na ocasião de sua tradução da Vida dos Filósofos de Diógenes Laércio. Ver carta a Huet de março de 1662, publicada em Ménage, Gilles. Lettres Inédites à Pierre-Daniel Huet. Napoli: Liguori Editore, 1993. Huet questionou a importância para a República das Letras do projeto de corrigir Moreri (ver correspondência com Nicaise publicada por Pélissier, op. cit., p. 36), entretanto leu e elogiou o Dicionário, como indica um fragmento de uma carta que escreveu a Graevius em maio de 1697 na qual afirma "multa in eo sunt solerter excogitata, scripta eleganter, erudite collecta" (c.f. Avenel, Joseph d'. Histoire de la vie et des ouvrages de Pierre-Daniel Huet évêque d'Avranches. Mortain: A. Lebel, 1853. p. 241). Podemos verificar 
conhecesse o manuscrito do Traité porque "he probably would have been very happy to find that the Bishop was a fellow sceptical-fideist". ${ }^{31} \mathrm{O}$ argumento implícito de Popkin é que se Bayle soubesse da existência do Traité, ele a divulgaria na República das Letras. Entretanto, como Huet era vivo e não queria que fosse pública a existência do Traité, e sobretudo sua autoria, é evidente que Bayle, que mantinha boas relações (ainda que mediadas) com Huet, jamais tornaria pública uma eventual satisfação em comungar idéias tão delicadas com o ilustre bispo.

Algumas afinidades entre o conteúdo do Traité philosophique e os argumentos céticos evocados pelo abade filosófico podem ser indicadas. Uma primeira, de caráter mais geral, é o fato do Traité elencar uma série de argumentos provenientes do ceticismo antigo - sobretudo do pirronismo de Sexto Empírico - e acrescentar a estes novos argumentos oriundos da nova filosofia, especificamente, de Gassendi, de Pascal (mostrando que a dúvida cartesiana não pode ser desfeita sem o auxílio da fé) e sobretudo de Descartes. ${ }^{32}$ Gassendi e Descartes são, juntamente com Simon Foucher, as fontes citadas pelo abade filosófico da nota B para mostrar o reforço que a nova filosofia traz para o ceticismo. Embora Huet não cite Foucher no Traité, ele conhecia bem as críticas de Foucher a Descartes e a Malebranche e apresenta como um dos seus principais argumentos o problema do véu das idéias colocado pela nova filosofia. $^{33}$

Estas afinidades gerais não são indicativas de que Bayle tenha lido um manuscrito do Traité, pois disponha das mesmas fontes de Huet. Uma outra afinidade é mais específica. O principal argumento do abade filosófico, que introduz a exposição da contradição entre os mistérios do cristianismo e os princípios da razão natural, é que todo dogmatismo pressupõe um critério de verdade e que este é a evidência. O problema do critério é detalhadamente tratado por Huet no capítulo 8 ('L'homme n'a point de regle certaine de la vérité”), onde retoma os argumentos de Sexto Empírico (PH II.18-79, M VII),

no prefácio da primeira edição do Dicionário que Bayle concordou com a objeção (que evidentemente poderia ter sido feito por outro ou por ele mesmo), dando-se conta da inutilidade para a República das Letras de corrigir Moreri. Entretanto, o projeto de correção erudita permaneceu, sendo este um aspecto que seria apreciado por Huet caso o bispo julgasse sua realização satisfatória. Lamentavelmente ainda não apareceu nenhuma reação específica do bispo de Avranches ao verbete Pirro.

31 Popkin, op. cit., p. 196.

32 Destes, Pascal não é jamais nomeado, Gassendi é referido nominalmente uma ou duas vezes e Descartes inúmeras. Ver Huet, Pierre-Daniel. Traité philosophique de la foiblesse de l'esprit humain. Amsterdam: Du Sauzet, 1723. p. 6, 42, 56, 66, 85-87, 92, 188, 194-196, 222, 234, 249, 269, 272, 284, 294.

33 'Seconde preuve. L'homme ne peut connoître avec une parfaite \& entiere Certitude, qu'un objet exterieur répond exactement à l'idée qui en este empreinte en lui», pp. 32-52. Huet possuía a maioria das obras de Foucher (ver inventário da biblioteca de Huet acima citado), com quem mantinha relações de amizade. 
sendo que no capítulo seguinte "on dispute contre l'evidence". O ataque de Huet à evidência neste capítulo é diferente do ataque do abade filosófico. ${ }^{34}$ Entretanto, as posições aproximam-se no capítulo II do segundo livro do Traité: "La foi suplee au défaut de la Raison, \& rend três certaine les choses, qui étoient moins certaines par la Raison". Citando Suarez, Huet afirma que a "lumiére de la foi" corrige e limita a validade de proposições "que parecem ser primeiros princípios" tal como o princípio de que duas coisas que são idênticas a uma terceira são idênticas entre si. Este princípio é limitado ou corrigido pelo mistério da trindade e, igualmente, por outros mistérios, sobretudo os da encarnação e da eucaristia. ${ }^{35} \mathrm{O}$ abade filosófico cita justamente estes três mistérios, e nesta mesma ordem, na parte do seu discurso que antecede a discussão moral.

$\mathrm{O}$ fato de Huet citar Suarez corrobora a tese de Jean-Luc Solère que a posição de Bayle de rejeitar a evidência indubitável como falsa face a sua contradição por um mistério revelado na Escritura se faz presente mesmo em escolásticos "ortodoxos". ${ }^{36}$ Uma qualificação que Solère faz neste ponto é também relevante nesta comparação entre Huet e Bayle: "la différence toutefois est que, chez [les "orthodoxes"], ce revirement ne se produit que pour certains points de doctrine inélucidables, et n'est pás généralisable à toute la dogmatique chrétienne". ${ }^{37}$ Eu diria que Huet, como Bayle, generaliza a limitação dos princípios da luz natural constatada face aos mistérios, sem contudo, diferentemente de Bayle, radicalizá-la. Observando que o princípio "de rien il ne se fait rien" "a été corrigé \& rejetté par la Foi", Huet indaga: "Pourquoi ne croirai-je pas qu'il en peut arriver autant aux autres Axiomes par la puissance de Dieu? Des Cartes n'a-t-il pas cru, qu'il se pouvoit faire par la puissance divine, qu'une même ... proposition fût vraye $\&$ fausse en même tems? D'où il s'ensuit manifestement, que lors que la Raison s'applique aux premier principes, quoi qu'elle y trouve une souveraine certitude humaine, il leur manque

$34 \mathrm{O}$ principal argumento de Huet contra a evidência é que ela pode nos enganar, como no caso de sonhos.

35 Traité, p. 185. Huet cita Suarez, Disputatio VI de Fide, Sect. V, Art II.: «Nous corrigeons souvent ... la lumiere naturelle par la lumiere de la Foi, même dans les choses qui semblent être des premiers principes, comme il paroît dans celui-ci : les choses qui sont les mêmes qu'une troisiéme chose, sont les mêmes choses entre elles ; ce qui dans la matiere de la Trinité doit être restreint aux choses finies. Et dans les autres Mysteres, principalement dans ceux de l'Incarnation \& de l'Eucharistie, nous apportons plusieurs autres limitations, afin que rien ne répugne à la Foi. C'est donc un signe que la lumiere de la Foi est plus certaine, parcequ'elle est fondée sur la premiere Verité, laquelle il est plus impossible qu'elle trompe ou qu'elle soit trompée, qu'il n'est impossible que la science naturelle de l'homme se trompe ».

36 Solère, Jean-Luc. "Bayle et les apories de la raison humaine" in Isabelle Delpla et Philippe de Robert (eds.) La Raison corrosive. Études sur la pensée critique de Pierre Bayle. Paris: Honoré Champion, 2003. p. 87137.

37 Solère, op. cit., p. 126n. 
néanmoins quelque chose pour être certains d'une parfaite certitude; \& que ce défaut est suppléé par la Foi». ${ }^{38}$

Esta posição intermediária entre a dos teólogos “ortodoxos" (os princípios são suspensos somente quando o entendimento considera os mistérios) e a do abade filosófico de Bayle (os princípios são suspensos absolutamente porque contradizem os mistérios) emerge no parecer favorável à ortodoxia que Huet fez de uma tese sustentada em Caen segundo a qual «il n'est pas évident qu'il y aye maintenant quelque vraye religion sur la terre». Huet explica que a tese não exclui « toute evidence ... mais [seulement] l'evidence metaphysique». ${ }^{39}$ Huet argumenta que negar que o cristianismo possua uma evidência metafísica não significa privar-se de toda base racional para afirmar sua verdade. Os católicos reconhecem que os mistérios da trindade e da eucaristia não são evidentes e nem por isto são libertinos. $\mathrm{O}$ abade filosófico da nota B cita os casos dos mistérios para afirmar que sua aceitação implica, se não a negação de toda evidência, a contraposição entre princípios igualmente evidentes, pois o princípio segundo o qual o que Deus revela é verdadeiro leva à aceitação de mistérios que negam, entre outros, o princípio da não contradição. Para Huet a religião cristã dispensa a evidência metafísica — que é limitada e corrigida, como vimos - mas possui evidência moral. Bayle não parece reconhecer esta última, mostrando-se bastante cético em relação às provas históricas que Huet apresenta na Demonstratio Evangelica ${ }^{40}$ Assim, se o abade filosófico é modelado no bispo de Avranches, o grande elogio terá passado por uma exaltação da fé_-aos olhos de Bayle_-maior do que a que transparece no "Traité philosophique de la foiblesse de l'esprit humain et de la force de la foi", complemento crucial presente no título de um manuscrito autógrafo de Huet descoberto por Popkin na Holanda e misteriosamente ausente da edição publicada por Du Sauzet. ${ }^{41}$ Segundo o testemunho do abade Olivet, ${ }^{42}$ Huet teria enviado o manuscrito do Traité para Reineer Leers, editor de Bayle, com a recomen-

38 Traité, p. 284.

39 Lettre de 27 mars 1693, Bibliothèque Laurenziana, Ashburnham Ms. 1866, Carteggio Huet, cassetta XIII, número 2435.

40 «La Demonstratio evangelica de Mr Huet fait voir à la verité que l' autheur a infiniment d'esprit, qu'il a une lecture prodigieuse, la plus belle latinité qu'on puisse demander d'un homme de ce tems, enfin une erudition profonde et une maniere de l'etaler fort agreable, mais au fonds il employe indifferemment les raisons probables et les raisons convainquantes, il fait fleche de tout bois, il appuye sur de faits qui ne sont gueres certains, comme le temoignage de Joseph en faveur de Jesus C., l'éclipse du soleil aveneu le jour de la passion non seulement à l'égard de la Judee, ce qui est de foy, mais aussi à l'égard des autre nations, ce qui n'est point vraisemblable, puis que les historiens grecs et romains qui vivoient en ce tems la, et qui ne pouvoient pas s'imaginer qu'un jour ce seroit un argument contre la religion payenne, n'en ont fait nulle mention» (Lettre à Jean Bayle, 1 avril 1679, CEuvres Diverses, Vol. III, 2004, lettre 165, p. 154-155).

41 Ver o relato de Popkin da descoberta deste manuscrito no Year Book of the APA, 1959, p. 449-53.

42 Ver carta de Olivet, publicada por Livet, 1858, Vol. II, p. 410-411. 
dação de publicá-lo sem o nome do autor e só após a sua morte. Mas como Leers faleceu antes de Huet, o manuscrito terminou sendo publicado por Du Sauzet, conhecido pela edição de obras heterodoxas como a Vida de Espinoza de Jean-Maximilian Lucas. ${ }^{43}$ Este episódio é indicativo da batalha travada na época entre usos cristãos e anti-cristãos do ceticismo que envolvia a produção, circulação e publicação de manuscritos clandestinos, nem todos, como o de Huet, anti-religiosos. Trata-se de um aspecto material da circulação de idéias a partir da Holanda do final do século XVII e início do XVIII que dificulta enormemente a avaliação objetiva das filosofias destes dois céticos. of Spinoza of 1719" In S. Beti, F. Charles-Daubert e R. H. Popkin (orgs.) Heterodoxy, Spinozism, and Free Thought in Early-Eighteenth-Century Europe. Dordrecht: Kluwer, 1996. p. 273-296. 